\title{
Factors affecting health seeking behavior for common childhood illnesses in Yemen
}

\author{
This article was published in the following Dove Press journal: \\ Patient Preference and Adherence \\ 22 October 2013 \\ Number of times this article has been viewed
}

\author{
Hana Hasan Webair \\ Abdulla Salim Bin-Gouth \\ Department of Family Medicine, \\ Hadhramout University of Science \\ and Technology, Almukalla, \\ Hadhramout, Yemen
}

Correspondence: Hana Hasan Webair Department of Family Medicine, Hadhramout University of Science and Technology, PO Box 8892, Almukalla, Hadhramout, Yemen Tel +967 733169896

Fax +9675327366

Email hhwebair@gmail.com
Introduction: Appropriate medical care seeking could prevent a significant number of child deaths and complications due to ill health. This study aims to determine factors affecting health seeking behavior (HSB) for childhood illnesses, thereby improving child survival.

Methods: A cross sectional study was carried out from January 11 to April 2, 2012. A total of 212 caretakers of children under the age of 5 years participated. Caretakers who visited the vaccination unit in the Shehair Health Center during the study period and had a child with a history of diarrhea, fever, cough, and/or difficulty of breathing during the last 14 days were included. The data were collected by interviewing caretakers and the answers were reported in pretested structured questionnaires.

Results: Medical care was sought for about half of the sick children ( $n=109,51.42 \%)$. Seeking medical care was frequently initiated for illnesses that did not improve or worsened. The major reasons for not seeking medical care were "illness was mild" $(n=40,38.83 \%)$ and "illness is not for medical treatment" $(\mathrm{n}=32,31.07 \%)$. The caretakers sought medical care significantly more when they had a higher level of school education (POR [prevalence odds ratio] 5.85, 95\% CI [confidence interval]: 2.34-14.61), when the illness was perceived as severe (POR 5.39, 95\% CI: 2.81-10.33), and when the child had difficulty of breathing (POR 2.93, 95\% CI: 1.10-7.80).

Conclusion: For the preventable childhood illnesses with existing interventions, appropriate HSB prevalence is low. Symptom type, caretakers' education, and perception of illness severity are the predictors of HSB. Educational improvement of the mothers, introduction of community based integrated management of childhood illness, and in-depth research are imperative to improve mothers' HSB.

Keywords: Shehair Health Center, childhood survival, cross sectional, medical care

\section{Introduction}

Children represent the most vulnerable age group in any community; therefore, the child mortality rate is widely used as a demographic measure and an important indicator of the level of welfare in countries. ${ }^{1}$

About 7 million children worldwide under the age of 5 years died in 2011. More than half of these deaths were due to preventable conditions where access to simple and affordable interventions was possible. Leading causes of death were pneumonia, preterm birth complications, diarrhea, birth asphyxia, and malaria. ${ }^{2}$ Undernutrition contributed to more than a third of these deaths. ${ }^{3}$

Overall, considerable progress has been made towards achieving Millennium Development Goal 4. Since 1990, the global under-5-year-old mortality rate (U5MR) has dropped from 87 deaths per 1,000 live births in 1990 to 51 deaths per 1,000 live births 
in 2011. But the rate of this reduction is still insufficient to reach the target of a two-thirds reduction of 1990 mortality levels by the year $2015 .^{2}$

However, success in reducing childhood mortality needs more than the availability of adequate health services with well-trained health professionals. As families are the first people responsible for child care, success requires a partnership between health workers and families with community support. ${ }^{4}$

Epidemiologists and social scientists have focused their attention on studying the relationship between childhood illnesses and health seeking behavior (HSB). ${ }^{5}$ Health or care seeking behavior has been defined as any action taken by someone in order to find an appropriate remedy for themselves or for the person whom they take care of, when they have a health problem or illness. ${ }^{6}$

In some low-income settings, child health and survival was improved when parents selected qualified medical care providers rather than nonqualified ones. ${ }^{7}$

Generally, there is a growing amount of literature on HSB and the predictors of health services utilization, especially in developing countries. ${ }^{8}$ Unfortunately, HSB studies often describe patterns of behavior without clarifying causes for that behavior, thereby failing to give valuable recommendations. ${ }^{9}$

Reviews of the global literature suggested that factors affecting HSB could be classified as cultural beliefs, sociodemographic status, women's autonomy, economic conditions, physical and financial accessibility, disease pattern, and health service issues. ${ }^{8,10-14}$ But, in developing countries, cultural practices and beliefs were the most prevalent. ${ }^{8}$ Cultural practices are prevalent in Yemen; these include massage, cauterization, and local herbal preparations. In addition, many people think that herbs are always useful and are never harmful (Bamatraf, unpublished data, 2008).

Unfortunately, no published quantitative studies have been found regarding the predictors of HSB for children in Yemen. In the last Yemen Family Health Survey (YFHS), data indicated that no medical care was sought for $53 \%$ and $61 \%$ of the children under five years of age with respiratory symptoms and diarrhea, respectively. ${ }^{15}$ Another Yemeni study described HSB for children with diarrhea but did not quantitatively determine its predictors (Bamatraf, unpublished data, 2008).

U5MR in Yemen is one of the highest in the Middle East. The World Health Organization reported it as being 77/1,000 live births, with the average regional and global rate as 68 and 57/1,000, respectively, in 2012. Apart from neonatal fatal conditions, pneumonia, followed by diarrhea, was the most frequent cause of death. ${ }^{16}$
This study therefore aims to determine the factors affecting HSB of caretakers when their children under the age of 5 years are suffering from common childhood illnesses such as diarrhea, fever, cough, and difficulty of breathing (DOB). Therefore, this study enables one to understand how to influence caretakers' behavior by a rational policy in order to promote child health. The objectives of the current study are to describe the caretakers' HSB, identify the rationale of HSB, and determine the relationship of HSB with subject, disorder, and service characteristics.

\section{Methods \\ Study design}

The study was carried out in Shehair city, which is an ancient city in Hadhramout Governorate, Yemen. It is classified as an urban city. ${ }^{17}$ It is located on the Arabian Sea coast, about $36 \mathrm{~km}$ from Almukalla (the capital of Hadhramout Governorate). The population was estimated to be 11,196 in 2011. The study was cross sectional.

\section{Participants}

The study targeted caretakers of children under the age of 5 years. The caretakers of children under 5 years of age with a history of diarrhea, fever, cough, and/or DOB during the preceding 14 days were included. Caretakers that had problems that might have affected the reliability of the questionnaire scores and those who refused to participate in the study were excluded.

\section{Sample}

All caretakers who met the inclusion criteria and visited the vaccination unit in Shehair Health Center (SHC) from January 11, 2012 were conveniently included until the required sample was completed by April 2, 2012. The total number of participants was 212 caretakers.

The required sample size was calculated from the prevalence of HSB in literature. The following formula was used to calculate sample size:

$$
\mathrm{n}>z 2 \times(\mathrm{p}) \times(1-\mathrm{p}) / \mathrm{c} 2
$$

where $z$ is the $z$ score ( 1.96 for $95 \%$ confidence level), $\mathrm{p}$ is the percentage picking a choice (it is substituted at 0.53 [avoiding seeking medical care in YFHS]), ${ }^{15} \mathrm{c}$ is the proportion of error we are prepared to accept (the current study set $<0.07$ ), and the required minimum sample size was 195 . Five percent was added for the possibility of nonresponse, so the minimum sample size became 205 caretakers. 


\section{Study variables}

There are many models for studying care seeking behaviors. Kroeger's sociobehavioral model covers the major dimensions of HSB. ${ }^{18}$ It is comprehensive and well-organized, so it enables the establishment of correlations with good predictability. ${ }^{19}$ This study depended on Kroeger's model in addition to the literature review in determining the study variables. Figure 1 shows the study variables.

Subject characteristics of the caretakers and children. Caretakers' data include age, marital status, education, occupation, and address. Children's data are age, sex, number of siblings, and child birth order. Disorder characteristics mean the severity and symptom type, ie, fever, diarrhea, cough, and/or DOB. Service characteristics include accessibility, acceptability, attitude towards traditional and modern medicine, quality of medical care, and affordability of medical care cost.

Sought medical care means consulted a qualified medical professional. Traditional healers are nonqualified persons who treat the sick children using traditional nonmedical methods such as massage, herbs, and cauterization. Drug sellers are nonqualified persons who sell drugs without medical prescription.

For inferential statistics, the caretakers' age and the number of siblings were classified into two categories according to the mean. The educational level was categorized according to the level of school education. ${ }^{20}$

Similarly, respondents' addresses were classified to three levels, one, two, and three, according to the geographic range and catchment area of the health facility for immunization activity (EPI-Program, unpublished data, 2011). Level two and three were merged into one category to avoid empty cells. Children were classified into infants and older. The birth order was divided into two categories based on the median.

Perception of severity of child illness was reported according to assessment using the caretakers' subjective evaluation. Diarrhea was defined as watery stools that occurred more than three times during any 24-hour period. ${ }^{21}$ DOB was defined as caretaker's perception of breathing as rapid and/or difficult. ${ }^{18}$ Cough was defined as a continuous cough. ${ }^{18}$ Fever was reported according to the caretakers' subjective evaluation.

\section{Data collection}

The data was collected by interviewing the respondents in SHC using a structured questionnaire formulated by the researcher and written in Arabic. A female community health worker was trained to assist in interviews. She was a native of the community and was deliberately chosen from the community to facilitate the flow of information.

The interviews were conducted in Arabic (Yemeni accent). The questionnaire covered the study objectives and variables and had five parts: subject characteristics; disorder characteristics; HSB patterns; HSB rationale; and services characteristics.

The questionnaire was validated by two steps. Firstly, a pilot survey of 30 caretakers from the target population

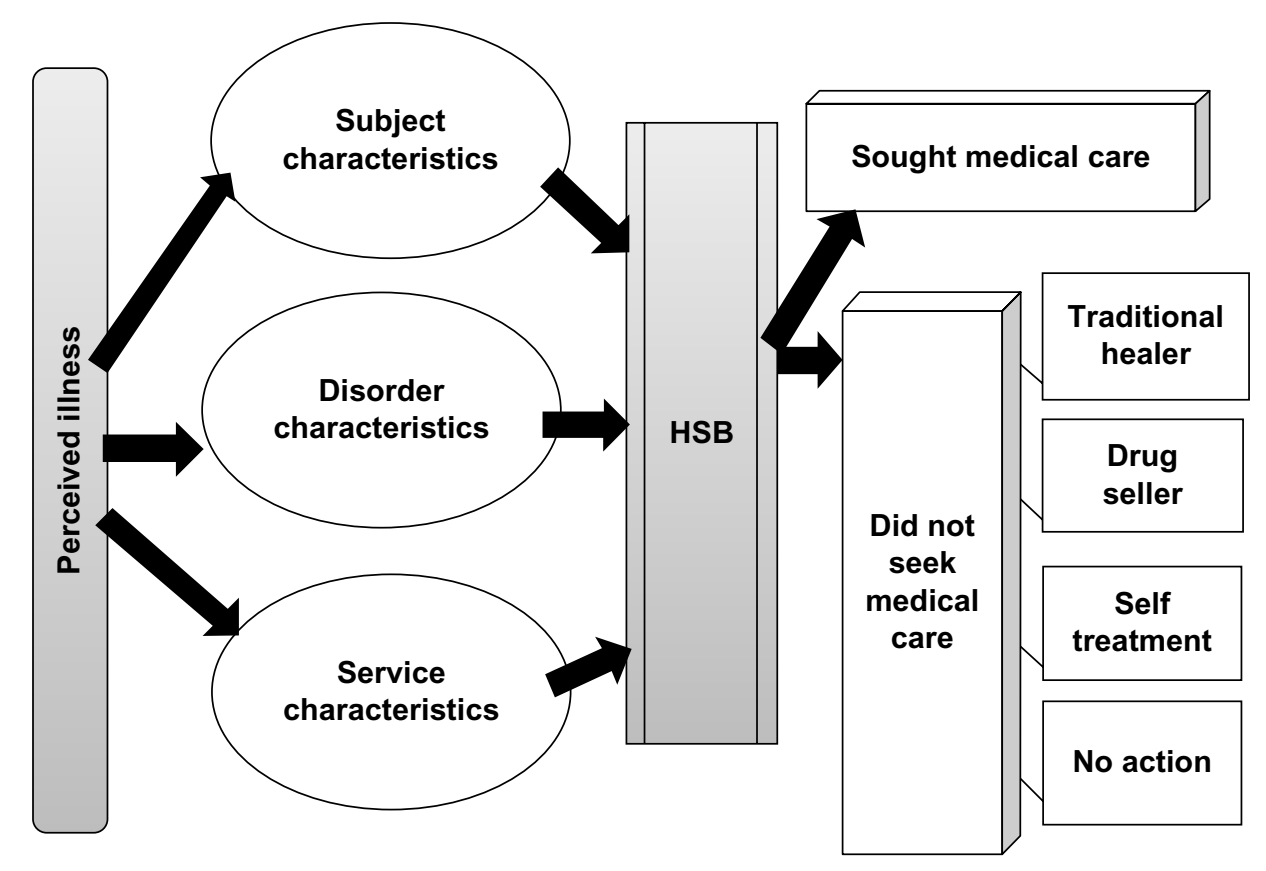

Figure I Factors affecting HSB for common childhood illnesses; study variables. Abbreviation: HSB, health seeking behavior. 
was conducted before the beginning of data collection. The pilot survey questionnaires were not included in the study because the questionnaire was modified in the light of the study findings. Secondly, five academic members of staff were asked to review the draft questionnaire. Most of them had conducted a study on HSB previously.

\section{Data analysis}

The data were coded, checked, and processed with version 20 Statistical Package for the Social Sciences (SPSS; IBM Corporation, Armonk, NY, USA). Summary statistics, such as means, standard deviations (SD), frequencies, and proportions, were used to summarize variables. Chi-square tests were used to identify associations between categorical variables with $P$-value $<0.05$ as the significance level. Logistic regression analysis was conducted to determine significant predictors of outcomes with estimation of the POR (prevalence odds ratio) and 95\% CI (confidence interval).

The Department of Family Medicine in Hadhramout University reviewed and approved the study protocol. A simple and clear explanation of the research aims and procedure was provided to the SHC manager and the staff involved in the study. Informed consents were obtained verbally from the manager and the staff who were included in the study. They were given feedback about the results of the study. Similarly, verbal consents were obtained from all of the caretakers who participated in the interviews. Respondents' privacy and confidentiality were assured.

\section{Results}

\section{Demographic characteristics}

All caretakers were adults with a mean age of 28 years $(\mathrm{SD} \pm 6)$. Age ranged from 18 to 45 years. Most of the caretakers were the mothers (98.58\%) while the remaining $1.42 \%$ were grandmothers and aunts. Regarding the age of children, the mean was 18 months ( $\mathrm{SD} \pm 17$ ) and it ranged from 10 days to 59 months. The median number of siblings was two; it ranged from 1 to 9. Table 1 shows the demographic characteristics of caretakers and children. The most common reported symptom was fever (76.89\%), followed by cough (35.85\%), diarrhea (29.25\%), and DOB (13.68\%). Around 58\% of the respondents (122) perceived their children's illnesses as severe.

\section{Description of HSB}

Out of 212 sick children, 109 (51.42\%) sought medical care, while $21(9.91 \%)$ caretakers did nothing in response to illnesses (Figure 2). The mean duration before seeking medical care was 3 days ( $\mathrm{SD} \pm 2$ ). Of the total number of
Table I Frequency distribution of caretakers and their sick children by demographic characteristics

\begin{tabular}{|c|c|c|}
\hline $\begin{array}{l}\text { Demographic characteristics } \\
\text { of caretakers and their children }\end{array}$ & Frequency & $\%(\mathbf{N}=\mathbf{2} \mid \mathbf{2})$ \\
\hline \multicolumn{3}{|l|}{ Caretakers characteristics } \\
\hline \multicolumn{3}{|l|}{ Caretaker of the child } \\
\hline The mother & 209 & 98.58 \\
\hline Not the mother & 3 & 1.42 \\
\hline \multicolumn{3}{|l|}{ Caretaker age (years) } \\
\hline$<25$ & 63 & 29.72 \\
\hline $25-<30$ & 58 & 27.36 \\
\hline $30-<35$ & 56 & 26.42 \\
\hline$\geq 35$ & 35 & $16.5 \mid$ \\
\hline \multicolumn{3}{|l|}{ Caretaker marital status } \\
\hline Married & 208 & 98.11 \\
\hline Widow/divorced & 4 & 1.89 \\
\hline \multicolumn{3}{|l|}{ Caretakers' educational level } \\
\hline Secondary school or higher & 49 & 23.11 \\
\hline Primary school & 105 & 49.53 \\
\hline No education & 58 & 27.36 \\
\hline \multicolumn{3}{|l|}{ Caretaker occupation } \\
\hline Housewife & 203 & 95.75 \\
\hline Not housewife & 9 & 4.25 \\
\hline \multicolumn{3}{|l|}{ Address level } \\
\hline Level one & 144 & 67.92 \\
\hline Level two and three & 68 & 32.08 \\
\hline \multicolumn{3}{|l|}{ Children characteristics } \\
\hline \multicolumn{3}{|l|}{ Age } \\
\hline$<12$ months & 114 & 53.77 \\
\hline 12-59 months & 98 & 46.23 \\
\hline \multicolumn{3}{|l|}{ Sex } \\
\hline Male & 107 & 50.47 \\
\hline Female & 105 & 49.53 \\
\hline \multicolumn{3}{|l|}{ Number of siblings } \\
\hline$\leq 2$ & 136 & 64.15 \\
\hline$>2$ & 76 & 35.85 \\
\hline \multicolumn{3}{|l|}{ Birth order } \\
\hline The first & 64 & 30.19 \\
\hline The second & 48 & 22.64 \\
\hline The third & 40 & 18.87 \\
\hline The fourth and higher & 60 & 28.30 \\
\hline
\end{tabular}

medically treated children, care was sought on the first day of perceived onset of illness for only 19 subjects (17.43\%). Although "sought medical care" was the most common pattern of HSB, it was the first action for only 56 (26.42\%) of respondents. The most common first action was "purchased drugs" (Table 2).

Decision was made by both parents for 75 (35.38\%) children. Sixty two $(29.25 \%)$ of the respondents stated that the decision was taken by the mother alone.

\section{Rationale of HSB}

For those who did not seek medical care, the main reason was stated as being "illness was mild" ( $n=40,38.83 \%)$, and 


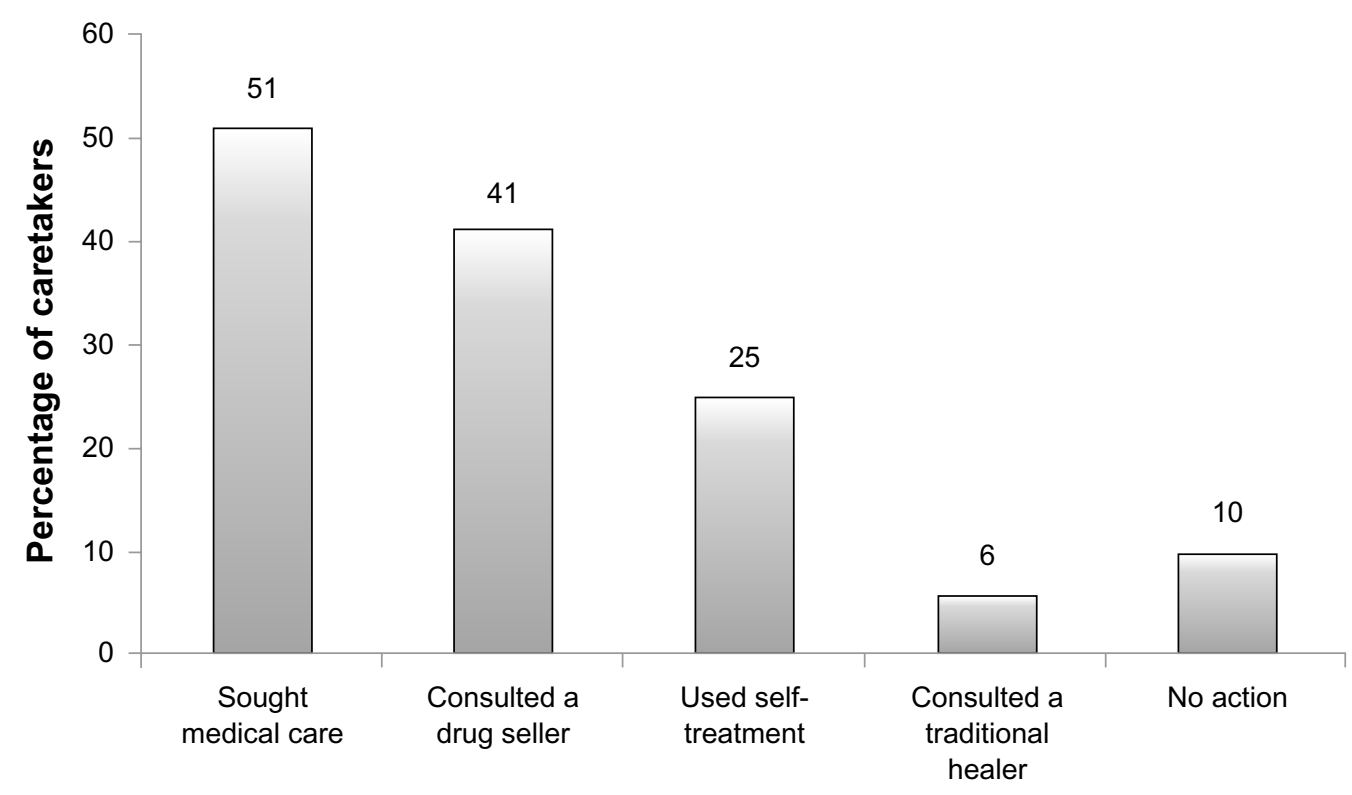

Source of care

Figure 2 Caretakers' distribution by the source of care.

the next most common cause was "illness is not for medical treatment" ( $\mathrm{n}=32,31.07 \%)$. The main reason for delaying seeking medical care for more than 3 days was "thought the illness was mild/will resolve” (66.32\%) (Figure 3).

\section{Relationship of HSB with subject, disorder, and service characteristics}

Regarding service characteristics, there was no statistically significant relationship between any of the services characteristics included in the questionnaire and HSB as $P$-values for all of them were $>0.05$ using Chi-square test. The respondents who agreed that the medical care cost was affordable sought medical care more frequently. For medical

Table 2 Distribution of caretakers by the order of action

\begin{tabular}{lll}
\hline HSB actions in order & Frequency & $\% \mathbf{~ ( N = 2 ~ I ~ 2 ) ~}$ \\
\hline $\begin{array}{l}\text { Sought any source of care } \\
\quad \text { Yes }\end{array}$ & 191 & 90.09 \\
$\begin{array}{l}\text { First action } \\
\text { Sought medical care }\end{array}$ & 56 & 26.42 \\
$\quad$ Consulted drug sellers & 80 & 37.74 \\
$\quad$ Used self-treatment & 46 & 21.70 \\
$\quad$ Consulted a traditional healer & 9 & 4.25 \\
Did any action after the first & & \\
Yes & 68 & 32.08 \\
Next actions & & \\
Sought medical care & 53 & 25.00 \\
Consulted drug sellers & 6 & 2.83 \\
$\quad$ Used self-treatment & 6 & 2.83 \\
$\quad$ Consulted a traditional healer & 3 & 1.42 \\
\hline
\end{tabular}

Abbreviation: HSB, health seeking behavior. services acceptability and attitude towards modern medicine, it was impossible to find the correlation as all the respondents answered with "Yes."

Table 3 shows the associations between HSB with subject and disorder characteristics. According to the bivariate analysis, significant associations were observed between HSB and the educational level of caretakers ( $P=0.003)$, the presence of cough $(P=0.047)$, having DOB $(P=0.005)$, and illness perception $(P<0.001)$. According to logistic regression analysis, caretakers with secondary school education were six times more likely to seek medical care than noneducated ones ( $\mathrm{POR}=5.85,95 \% \mathrm{CI}: 2.34-14.61$ ). Perceiving illnesses as severe was five times more likely to be associated with medical care seeking as compared to not severe $(\mathrm{POR}=5.39$, 95\% CI: 2.81-10.33). For those who had DOB, the caretakers were three times more likely to seek medical help than those who did not ( $\mathrm{POR}=2.93,95 \% \mathrm{CI}: 1.10-7.80)$. Cough is no longer significant after adjustment of other variables using logistic regression analysis.

\section{Discussion}

In studying HSB in Shehair city, the current study found that $51.42 \%$ of the respondents sought medical care, this being the most frequent action.

YFHS and other studies similarly showed that around half of the respondents sought medical care., ${ }^{5,22}$ Better results and higher rates of medical care seeking were reported in some countries, ${ }^{23-28}$ while others showed lower rates. ${ }^{24,29,30}$ 
$\square$ Causes of delaying seeking medical care

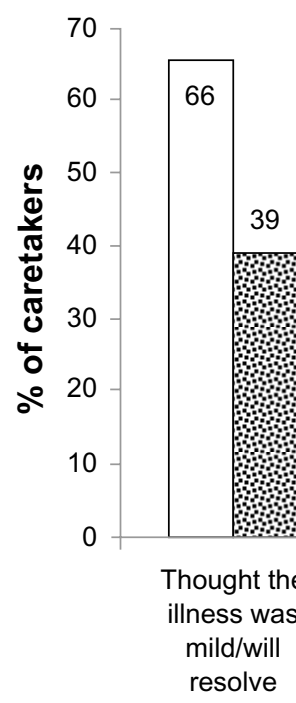

39

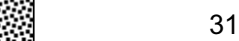

3)
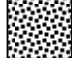

10

x

Illness is not for medical treatment

영 Causes of avoiding seeking medical care

צ. 15

\%

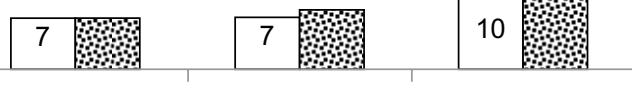

Didn't have enough money

Transportation difficulties

Others

\section{Causes}

Figure 3 Causes of delaying and avoiding seeking medical care.

Variation in HSB could be attributed to differences in cultural and demographic features of the samples, because most of these studies are not based on national or regional samples. In addition, the spectrum of the illness used differed between some of the studies.

The least frequent action was consulting traditional healers followed by self-treatment. In the study in Almukalla, Yemen, consulting traditional healers was the most frequent action (Bamatraf, unpublished data, 2008). That study included diarrhea only, which was experienced by less than one third of the children in the current study. Promtussananon and Peltzer ${ }^{31}$ concluded that most mothers used home remedies for the treatment of diarrhea and modern drugs for the treatment of fever and cough, which might explain the differences between these studies in Yemen.

Although seeking medical care was the most frequent HSB pattern in this study, it was not usually done as the first choice. The most frequent first response was purchasing over-the-counter drugs. Bamatraf (unpublished data, 2008), and a study in South Africa, found that treatment by home remedies was the most frequent first action by caretakers for children with diarrhea. ${ }^{31}$

Mothers were the caretakers for nearly all the children and participated in decision making in more than $60 \%$ of cases, which corresponds with the study in Almukalla (Bamatraf, unpublished data, 2008). For most of the people in developing countries, and particularly for children, the type of treatment during illness cases is mainly decided by family members, especially the mothers. ${ }^{1}$ Low decision-making power of women impacted negatively on HSB in the study areas. ${ }^{32}$
Actually, it is difficult to determine the most appropriate time to take the sick child to medical providers because this depends on the illness itself, the health status of the child, the caretaker, and so forth; but, with no doubt, delay is not acceptable, especially in a country with a high U5MR like Yemen.

Uncomplicated illnesses could be managed at home, but severe illnesses should be treated by appropriate health providers without delay. ${ }^{33}$ The current study documented that 122 caretakers perceived the illnesses as severe, but only 19 of them took their children for medical care during the first day of illness. Other studies similarly recorded some delay in medical care seeking. ${ }^{22,32,34}$ In a Nepalese study, about $43 \%$ of those who sought medical advice did so within 24 hours. ${ }^{29}$

Delay in care-seeking by caregivers contributes to the large number of child deaths in developing countries. ${ }^{35}$ Factors such as pluralistic care-seeking practices, and the inability to recognize potentially life-threatening conditions, were found to be associated with the delay. ${ }^{7}$ This delay could affect child health significantly and can lead to complications that make the medical care less effective and, in some cases, useless.

In 2008, Bamatraf stated that most of the children with diarrhea were taken to medical care only after home treatments and those of traditional healers failed (Bamatraf, unpublished data, 2008). During that time a child may become severely dehydrated. For that reason, it is very important to address and deal with the causes of delay.

In reviewing literature, studies rarely discussed the rationale of delayed medical care despite the fact that many 
Table 3 Relationship between HSB and subject and disorder characteristics

\begin{tabular}{|c|c|c|c|c|}
\hline \multirow[t]{2}{*}{ Variable (N) } & \multicolumn{2}{|l|}{ Bivariate analysis } & \multicolumn{2}{|c|}{ Logistic regression } \\
\hline & Sought medical care & Chi-square ( $P$-value) & POR & $95 \% \mathrm{Cl}$ \\
\hline \multicolumn{5}{|l|}{ Caretakers' age (years) } \\
\hline$\geq 28(121)$ & $55(45.45)$ & $2.35(0.477)$ & & \\
\hline$>28(9 \mathrm{I})$ & $49(53.85)$ & & & \\
\hline \multicolumn{5}{|l|}{ Caretakers' educational level } \\
\hline Secondary or higher (49) & $33(67.35)$ & $11.79(0.003)$ & 5.85 & $2.34-|4.6|$ \\
\hline Primary school (105) & $56(53.33)$ & & & \\
\hline No education (58) & $20(34.48)$ & & & \\
\hline \multicolumn{5}{|l|}{ Address level } \\
\hline Level one (I44) & $79(54.86)$ & $2.13(0.317)$ & & \\
\hline Level two and three (68) & $30(44.12)$ & & & \\
\hline \multicolumn{5}{|l|}{ Child age } \\
\hline$<12$ months (II4) & $58(50.88)$ & $0.03(0.490)$ & & \\
\hline I2-59 months (98) & $5 \mathrm{I}(52.04)$ & & & \\
\hline \multicolumn{5}{|l|}{ Child sex } \\
\hline Male (I07) & $58(54.21)$ & $0.67(0.4 I 2)$ & & \\
\hline Female (105) & $5 \mathrm{I}(48.57)$ & & & \\
\hline \multicolumn{5}{|l|}{ Sibling number } \\
\hline$\leq 2(136)$ & $69(50.74)$ & $0.07(0.79 \mid)$ & & \\
\hline$>2(76)$ & $40(52.63)$ & & & \\
\hline \multicolumn{5}{|l|}{ Birth order } \\
\hline The first or second (II2) & $62(55.36)$ & I.48 (0.224) & & \\
\hline After second $(100)$ & $47(47.00)$ & & & \\
\hline \multicolumn{5}{|l|}{ Fever } \\
\hline Yes (I63) & $89(54.60)$ & $2.87(0.090)$ & & \\
\hline No (49) & $20(40.82)$ & & & \\
\hline \multicolumn{5}{|l|}{ Cough } \\
\hline Yes (76) & $46(60.53)$ & $3.94(0.047)$ & 1.57 & $0.82-2.99$ \\
\hline No (136) & $63(46.32)$ & & & \\
\hline \multicolumn{5}{|l|}{ DOB } \\
\hline Yes (29) & $22(75.86)$ & $8.04(0.005)$ & 2.93 & $1.10-7.80$ \\
\hline No (183) & $87(47.54)$ & & & \\
\hline \multicolumn{5}{|l|}{ Diarrhea } \\
\hline Yes (62) & $32(51.61)$ & $0.00(0.970)$ & & \\
\hline No $(150)$ & $77(51.33)$ & & & \\
\hline \multicolumn{5}{|l|}{ Perception of illness } \\
\hline Severe (122) & $82(67.21)$ & $28.71(0.000)$ & 5.39 & $2.81-10.33$ \\
\hline Not severe $(90)$ & $27(30.00)$ & & & \\
\hline
\end{tabular}

Note: The values in bold are statistically significant $P$-values and confidence intervals.

Abbreviations: HSB, health seeking behavior; POR, prevalence odds ratio; $\mathrm{Cl}$, confidence interval; $\mathrm{DOB}$, difficulty of breathing.

mentioned the duration of illness before care seeking. Some studies have documented a popular belief that a patient has to be very ill to warrant taking him or her to the hospital as well as the reliance on traditional healers and the preference for trying self-medication prior to consulting medical professionals. $^{32}$

The main reason for not seeking medical care in the current study was "The illness was mild." This is in agreement with several other studies..$^{15,25,36}$ The next common reason was "Illness is not for medical treatment." ${ }^{37}$ This pointed to the traditional illness concepts of childhood symptoms, which are believed to be a result of nonmedical mechanisms and preferably treated by traditional healers or home remedies. ${ }^{38}$
A study in Burkina Faso showed that local illness concepts about manifestations of severe malaria in Africa were associated with avoidance or significant delay of effective biomedical treatment. Thus, they recommended considering these concepts when developing specific educational messages within national malaria control programs. $^{38}$

The findings of the current study are an indication that households seem to have shifted from making use of professional medical services as a trusted source of care to, instead, taking it as the last solution after trying other trusted methods. The situation here is dangerous for the general health of the population and, therefore, must be corrected. 
Ashorn ${ }^{1}$ in his study in Malawi found the variables that describe the type of the first treatment to be statistically significantly associated with childhood mortality. On the other hand, the analysis of the second treatment brought considerably fewer statistically significant relationships with childhood mortality.

Considering the factors affecting HSB, several studies have reported a positive relationship between maternal education and HSB, which is in agreement with the present study. ${ }^{24,27,29,30,39,40}$ Millennium Development Goals' last report stated that, within countries, child mortality is higher in rural areas and among poorer and less educated families. ${ }^{20}$

This study shows that caretakers with secondary school education were six times more likely to seek medical care than noneducated ones. This implies that the higher the level of school education, the better HSB. School education increases the mother's knowledge about biological aspects of human beings, common health problems, and healthy habits as these are included in standard school curricula. Also, educated mothers are more likely to be able to read comprehensibly and thereby understand better. They are expected to understand health education messages presented in mass media and through other methods more than the less-educated ones. Other subject characteristics listed in the results were insignificant.

Regarding disorder characteristics, caretakers were more likely to seek medical treatment when a child experienced DOB. YFHS and another two studies reported similar findings. ${ }^{15,18,31}$ This finding differs to that which Mbagaya and Odhiambo ${ }^{30}$ and Taffa and Chepngeno ${ }^{41}$ found among Kenyan mothers, who were much more likely to seek out a medical care provider when a child experienced fever and gastrointestinal symptoms than when suffering from respiratory symptoms.

These studies included a wider range of respiratory symptoms. Usually, little or no action is taken for upper respiratory symptoms because it is assumed they will heal in their own time..$^{30}$ Those studies were done in Kenya, so another explanation is that both the identification of and response to illnesses are closely linked to cultural beliefs. ${ }^{1}$

Perceiving the illness as severe was strongly associated with seeking medical care in the current study. Many studies found it to be one of the main predictors of HSB. ${ }^{1,5,24,29,36,39}$ It has been maintained that, in general, people use first what is most easily available to them, but in cases of serious illnesses they are willing to make a greater effort in order to try something better. ${ }^{1}$
None of the service characteristics significantly predicted HSB in this study, although mothers who could afford the cost of care sought medical care more frequently than others.

When comparing this finding with those of other published studies, many did not consider services characteristics, and others have contrasting results. Several studies reported distance from medical care facility, poor facilities, or inability to afford medical care cost as factors affecting HSB. $8,27,30,32,42,43$

Disagreement between studies regarding the significance of service characteristics could be explained by the sample differences, for example, studies in which samples were selected from large areas with a population of different characteristics, variable distances from health facilities, and multiple health service options would be more likely to prove the significance of association.

It is important to understand the limitations of the current study. It is known that the community based survey is a better choice for sampling in a study like this, but it requires team work and financial support that is beyond the scope of a study done by two researchers. Visitors of SHC vaccination unit were selected because all of them had children under 5 years old and were not coming for illnesses to gain medical care but for vaccination. Another point is that the vaccination coverage in $\mathrm{SHC}$ is more than $90 \%$, which indicates that women come from almost all areas of Shehair, rendering the sample more representative.

There was a possibility of inaccurate responses regarding the disease characteristics as this largely depends on recall. The study included illnesses within 14 days before the interview to minimize the recall bias. ${ }^{5,26,29,40,43}$

Furthermore, the present study did not address in depth the health and illness beliefs. To explore HSB of a population in depth, it needs a qualitative or mixed study with a team including anthropologists and/or social scientists to conduct ethnographic research. This is not available for the time being. The current study is an observational study. It could not prove any causal relationship between HSB and the factors affecting it.

In conclusion, for the preventable childhood illnesses with the existing interventions, appropriate HSB prevalence is low. Caretakers' education, symptom type, and perception of illness severity are the predictors of HSB.

Educational improvement of mothers is recommended. We place emphasis on literacy programs because around $27 \%$ of the respondents had no school education. Messages in the mass media about the importance of schooling are mandatory. 
Further research to explore the barriers of school education are expected to help in solving the problem. Introduction of community-based Integrated Management of Childhood Illness programs could facilitate behavior change. Formal and nonformal medical care options have great potential for successful implementation to improve child health and should be explored by health policies. Local illness concepts could be explored and used effectively as a part of care seeking interventions as this is found to be one of the main causes of avoiding and delaying seeking medical care. In-depth research is imperative to visualize the real picture of the habits and practices of the people of our country, and to establish the causation of inappropriate HSB. More challenging would be the translation of research into policy and action.

\section{Acknowledgments}

This paper is based on a Masters thesis at Hadhramout University of Science and Technology. We thank the referees of the thesis, Dr Mosleh Ismail and Professor Abdullhakeem Lardhi, for their constructive comments. The authors are gratefully indebted to mothers and SHC's staff who participated in and supported the study interviews. We additionally would like to thank Dr Fouziya Bamatraf, Dr Chandrashekhar Sreeramareddy, Dr Diana Sacke, and Anne-Laure Page for their helpful comments on the study methodology. We are thankful to the editor Dr Johnny Chen and the reviewers for insightful comments on the previous version of this paper.

\section{Disclosure}

The authors report no conflicts of interest in this work.

\section{References}

1. Ashorn U. Child health-seeking in Lungwena, Malawi [academic dissertation]. Tampere: University of Tampere; 2003.

2. Children: reducing mortality [webpage on the internet]. Geneva: World Health Organization; 2012. Available from: http://www.who.int/ mediacentre/factsheets/fs178/en/index.html. Accessed October 12, 2012.

3. Johansson EW, Carvajal L, Newby H, Young M. Pneumonia and Diarrhoea: Tackling the Deadliest Diseases for the World's Poorest Children. New York: UNICEF; 2012. Available from: http://www.unicef.org/ media/files/UNICEF_P_D_complete_0604.pdf. Accessed December 27, 2012.

4. Child health in the community - "Community IMCI": briefing package for facilitators [webpage on the internet]. Geneva: World Health Organization; 2004. Available from: http://www.who.int/maternal_child_ adolescent/documents/9241591951/en/index.html. Accessed June 29, 2012.

5. Goldman N, Heuveline P. Health-seeking behaviour for child illness in Guatemala. Trop Med Int Health. 2001;5(2):145-155.

6. Olenja J. Editorial Health seeking behaviour in context. East Afr Med J. 2003;80(2):61-62.

7. D'Souza RM. Role of health-seeking behaviour in child mortality in the slums of Karachi, Pakistan. J Biosoc Sci. 2003;35(1):131-144.
8. Shaikh BT, Hatcher J. Health seeking behaviour and health service utilization in Pakistan: challenging the policy makers. J Public Health (Oxf). 2005;27(1):49-54.

9. Grundy J, Annear P. Health-Seeking Behaviour Studies: a Literature Review of Study Design and Methods with a Focus on Cambodia. Australia: University of Melbourne, The Nossal Institute for Global Health; 2010. 77 p. Available from: http://ni.unimelb.edu.au/_data/assets/ pdf_file/0011/385967/HPHF_Hub_WP7_Health_Seeking_Behaviour. pdf. Accessed June 11, 2012.

10. Katung PY. Socio-economic factors responsible for poor utilization of PHC services in rural community in Nigeria. Niger $J$ Med. 2001;10:28-29.

11. Navaneetham K, Dharmalingam A. Utilization of maternal health care services in Southern India. Soc Sci Med. 2002;55:1849-1869.

12. Fatimi Z, Avan I. Demographic, Socio-economic and Environmental determinants of utilization of antenatal care in rural setting of Sindh, Pakistan. J Pak Med Assoc. 2002;52:138-142.

13. Uchudi JM. Covariates of child mortality in Mail: does the health seeking behavior of the mother matter? J Biosoc Sci. 2001;33:33-54.

14. Stephenson R, Hennink M. Barriers to family planning service use among the urban poor in Pakistan. Asia Pac Popul J. 2004;19:5-26

15. League of Arab States, Republic of Yemen Ministry of Health and Population. Yemen Family Health Survey Principal Report. Sanaa: Central Statistical Organization (CSO); 2004.

16. Data from the Global Health Observatory: Country health profile [webpage on the internet]. Geneva: World Health Organization, 2013. Available from: http://www.who.int/gho/countries/yem.pdf. Accessed May 21, 2012.

17. Social Fund for Development: Programming Unit. Educational Survey. Yemen: Ministry of Education; 2008.

18. Sakisaka K, Jimba M, Hanada K. Changing poor mothers' care-seeking behaviors in response to childhood illness: findings from a crosssectional study in Granada, Nicaragua. BMC Int Health Hum Rights. 2010;10(1):10.

19. Hausmann-Muela S, Ribera JM, Nyamongo I. Health-Seeking Behavior and the Health System Response: Disease Control Priorities Project; Aug 2003. 37 p. DCPP Working Paper No 14. Available from: http:// dcp2.org/file/29/wp14.pdf. Accessed April 15, 2012.

20. Inter-Agency and Expert Group on MDG Indicators. The Millennium Development Goals Report 2012. New York: United Nations; 2012. Available from: www.undp.org/content/dam/undp/library/MDG/ english/The_MDG_Report_2012.pdf. Accessed December 24, 2012.

21. Diarrheal Disease [webpage on the internet]. Geneva: World Health Organization. Available from: http://www.who.int/mediacentre/ factsheets/fs330/en/index.html. Accessed April 27, 2012.

22. Assefa T, Belachew T, Tegegn A, Deribew A. Mothers' health care seeking behaviour for childhood illnesses in Derra District, Northshoa Zone, Oromia Regional State, Ethiopia. Ethiop J Health Sci. 2008;18(3):87-94.

23. Ndugwa RP, Zulu EM. Child morbidity and care-seeking in Nairobi slum settlements: the role of environmental and socio-economic factors. J Child Health Care. 2008;12(4):314-328.

24. Abdulraheem IS, Parakoyi DB. Factors affecting mothers' healthcareseeking behaviour for childhood illnesses in a rural Nigerian setting. Early Child Dev Care. 2009;179(5):671-683.

25. Page AL, Hustache S, Luquero FJ, Djibo A, Manzo ML, Grais RF. Health care seeking behavior for diarrhea in children under 5 in rural Niger: results of a cross-sectional survey. BMC Public Health. 2011; 11:389.

26. Motlagh ME, Heidarzadeh A, Hashemian H, Dosstdar M. Patterns of Care Seeking During Episodes of Childhood Diarrhea and its Relation to Preventive Care Patterns: National Integrated Monitoring and Evaluation Survey (IMES) of Family Health. Islamic Republic of Iran. Int $J$ Prev Med. 2012;3(1):60-67.

27. Gao W, Dang S, Yan H, Wang D. Care-seeking pattern for diarrhea among children under 36 months old in Rural Western China. PLOS One. 2012;7(8):e43103. 
28. Global health observatory: Care seeking for pneumonia: situation and trends [webpage on the internet]. Geneva: World Health Organization. Available from: http://www.who.int/gho/child_health/prevention/ pneumonia_text/en/index.html. Accessed July 12, 2012.

29. Sreeramareddy CT, Shankar RP, Sreekumaran BV, Subba SH, Joshi HS, Ramachandran U. Care seeking behaviour for childhood illness-a questionnaire survey in western Nepal. BMC Int Health Hum Rights. 2006;6:7.

30. Mbagaya GM, Odhiambo MO, Oniang'o RK. Mother's health seeking behaviour during child illness in a rural western Kenya community. Afr Health Sci. 2007;5(4):322-327.

31. Promtussananon S, Peltzer K. Health care-seeking behaviour for child illnesses among rural mothers in South Africa: a pilot study. Health SA Gesondheid. 2003;8(2).

32. Mazzilli C, Davis A. Health Care Seeking Behaviour in Somalia - A Literature Review. Somalia: UNICEF and the European Union; 2009. 52 Available from: www.unicef.org/somalia/SOM_ HealthcareseekingbehaviourReport_10-WEB.pdf. Accessed March 2, 2012.

33. Fujino Y, Sasaki S, Igarashi K, et al. Improvement in mothers' immediate care-seeking behaviors for children's danger signs through a community-based intervention in Lusaka, Zambia. Tohoku J Exp Med. 2009;217(1):73-85.

34. Najnin N, Bennett CM, Luby SP. Inequalities in Care-seeking for Febrile Illness of Under-five Children in Urban Dhaka, Bangladesh. J Health Popul Nutr. 2011;29(5):523-531.

35. Källander K, Hildenwall H, Waiswa P, Galiwango E, Peterson S, Pariyo G. Delayed care seeking for fatal pneumonia in children aged under five years in Uganda: a case-series study. Bull World Health Organ. 2008;86(5):332-338.
36. Amuyunzu-Nyamongo M, Nyamongo IK. Health seeking behaviour of mothers of under-five-year-old children in the slum communities of Nairobi, Kenya. Anthropol Med. 2006;13(1):25-40.

37. Hill Z, Kendall C, Arthur P, Kirkwood B, Adjei E. Recognizing childhood illnesses and their traditional explanations: exploring options for care-seeking interventions in the context of the IMCI strategy in rural Ghana. Trop Med Int Health. 2003;8(7):668-676.

38. Beiersmann C, Sanou A, Wladarsch E, De Allegri M, Kouyaté B, Muller O. Malaria in rural Burkina Faso: local illness concepts, patterns of traditional treatment and influence on health-seeking behaviour. Malar J. 2007;6:106.

39. Hong TK, Dibley MJ, Tuan T. Factors affecting utilization of health care services by mothers of children ill with diarrhea in rural Vietnam. Southeast Asian J Trop Med Public Health. 2003;34(1):187-198.

40. Amin R, Shah NM, Becker S. Socioeconomic factors differentiating maternal and child health-seeking behavior in rural Bangladesh: A cross-sectional analysis. Int J Equity Health. 2010;9:9.

41. Taffa N, Chepngeno G. Determinants of health care seeking for childhood illnesses in Nairobi slums. Trop Med Int Health. 2005;10(3): 240-245.

42. Feikin DR, Nguyen LM, Adazu K, et al. The impact of distance of residence from a peripheral health facility on pediatric health utilisation in rural western Kenya. Trop Med Int Health. 2009;14(1):54-61.

43. Ewing VL, Lalloo DG, Phiri KS, Roca-Feltrer A, Mangham LJ, SanJoaquin MA. Seasonal and geographic differences in treatmentseeking and household cost of febrile illness among children in Malawi. Malar J. 2011;10:32.
Patient Preference and Adherence

\section{Publish your work in this journal}

Patient Preference and Adherence is an international, peer-reviewed, open access journal focusing on the growing importance of patient preference and adherence throughout the therapeutic continuum. Patient satisfaction, acceptability, quality of life, compliance, persistence and their role in developing new therapeutic modalities and compounds to

\section{Dovepress}

optimize clinical outcomes for existing disease states are major areas of interest. This journal has been accepted for indexing on PubMed Central. The manuscript management system is completely online and includes a very quick and fair peer-review system. Visit http://www.dovepress.com/ testimonials.php to read real quotes from published authors. 